Bogolyubov Institute for Theoretical Physics, Nat. Acad. of Sci. of Ukraine (14b, Metrolohichna Str., Kyiv 03680,Ukraine; e-mail: vgrytsay@bitp.kiev.ua)

PACS 05.45.-a, 05.45.Pq, 05.65. $+\mathrm{b}$

\title{
SELF-ORGANIZATION AND CHAOS IN THE METABOLISM OF HEMOSTASIS IN A BLOOD VESSEL
}

\begin{abstract}
A mathematical model of the metabolic process of formation of the hemostasis in a bloodcarrying vessel is constructed. As distinct from the earlier developed model of the multienzyme prostacyclin-thromboxane system of blood, this model includes, for the first time, the influence of the level of "bad cholesterol", i.e., low-density lipoproteins (LDLs), on the hemostasis. The conditions, under which the self-organization of the system appears, and the modes of autooscillations and chaos in the metabolic process, which affects the formation of hemostasis and the development of thrombophilia, are found. With the aid of a phase-parametric diagram, the scenario of their appearance is studied. The bifurcations of doubling of a period and the transition to chaotic oscillations as a result of the intermittence are found. The obtained strange attractors are formed due to a mixing funnel. The full spectra of Lyapunov's exponents, KS-entropies, "predictability horizons", and Lyapunov's dimensions of strange attractors are calculated. The reasons for a change in the cyclicity of the given metabolic process, its stability, and the physiological manifestation in the blood-carrying system are discussed. The role of physiologically active substances in a decrease in the level of cholesterol in blood vessels is estimated.

Ke ywords: hemostasis, LDLs, self-organization, strange attractor, phase-parametric diagram, Lyapunov's exponents, KS-entropy.
\end{abstract}

Multicellular organism is a holistic system, whose cells are specialized for the execution of various functions. Their structural-functional connections form the self-organization in the system. The interaction inside organism is realized via complex regulating, coordinating, and correcting mechanisms with participation of neural, humoral, exchanging, and other processes. Many separate mechanisms, which regulate internal cellular and intercellular mutual relations, form opposite (antagonistic) actions, by balancing one another. This leads to the establishment of a variable physiological equilibrium in organism, which allows an alive system to hold a relative dy-

(C) V.I. GRYTSAY, 2016

648 namical stationary state, despite the changes in the environment and the variations arising in the process of vital activity of organism. From the viewpoint of biophysics, it is a state, in which all processes responsible for the energetic transformations in organism are in a dynamical equilibrium. Such state is called the homeostasis.

The blood composition steadiness has a special meaning for the vital activity of organism. Two antagonistic systems exist in blood vessels: those responsible for the coagulation and anticoagulation of blood. Due to their presence, the functional equilibrium, which hampers the coagulation of blood inside vessels, is formed. This state is called the hemostasis [1-4].

ISSN 2071-0194. Ukr. J. Phys. 2016. Vol. 61, No. 7 
But if the wall of a vessel is damaged, the blood flow decelerates, or the functional state of the system of hemostasis is changed, then the conditions for the development of thrombophilia and thrombosis arise.

The regulators of the coagulation of blood are thromboxanes and prostacyclins. Thromboxanes and prostacyclins are created, respectively, in thrombocytes and in endothelial internal cells of a vessel. The high level of thromboxanes favors the aggregation of thrombocytes, which leads to the coagulation of blood. On the contrary, prostacyclins hamper the coagulation of blood, being the inhibitors of the aggregation of thrombocytes. The establisnment of a dynamical equilibrium between those systems leads to the establishment of a hemostasis.

A number of researchers modeled this and other analogous processes [5, 8]. Those calculations were partially carried out with participation of the author. Later with the use of those results, a mathematical model of a multienzyme prostacyclin-thromboxane system of blood was developed in [9-12]. With the use of the theory of dissipative structures, the conditions of self-organization of the system and the appearance of stationary stable autoperiodic oscillations were found. Moreover, the conditions of appearance of hemophilia and thrombosis and the physiological influence of autooscillatory modes on the bloodcarrying system were studied.

In the present work, we continue the study of this system with regard for the presence of cholesterol in blood.

One of the basic factors affecting the functional state of hemostasis is the level of "bad cholesterol" in blood. It is determined by the level of lowdensity lipoproteins (LDLs). At its excess concentration, atherosclerosis of vessels develops [13-16].

The excess of these particles penetrates into the arterial wall, by accumulating in it. In this case, their chemical formula is changed. Modified LDLs stimulate endothelial cells to the activation of adhesion receptors, which join monocytes of blood and $\mathrm{T}$ cells. In addition, endothelial cells give off a secretion, namely, chemokines, which entice monocytes in a trap of intima. In intima, monocytes ripen and become active macrophages. They absorb LDLs, by filling themselves with drops of fat. These foamy fatloaded macrophages and T-cells form fat strips, which are predecessors of complex arterial patches, which

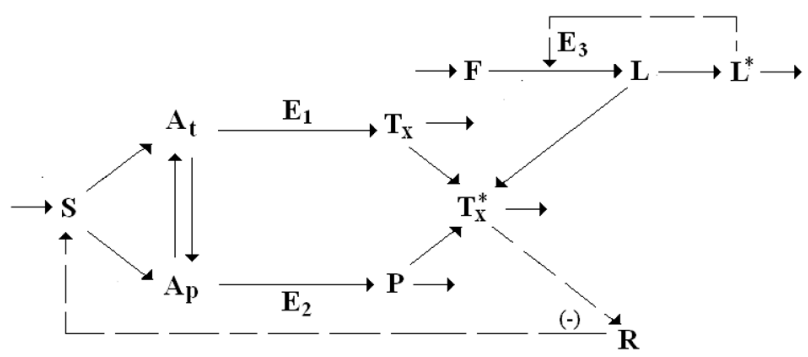

Fig. 1. General kinetic diagram of the hemostasis of a blood vessel

disfigure arteries later on. Molecules from inflammation can favor the further growth of a patch and the formation of a fibrous cap above the lipid core, which causes the stenosis of a vessel. The further growth of a patch can cause its rupture and the appearance of thrombosis.

We will study the influence of LDLs on the selforganization of the metabolic process of hemostasis in blood vessels and on the appearance of thrombophilia. The role of drugs for the purification of blood vessels from cholesterol will be evaluated.

\section{Mathematical Model}

We will construct a mathematical model according to the general diagram of the hemostasis of a blood vessel, which is presented in Fig. 1.

This system is open and nonequilibrium. For it, the input substance is irreplaceable arachidonic fat acid $S$, which enters blood from digestive tract. Under the action of phospholipases, it is accumulated in thrombocytes $A_{t}$ and endothelial cells $A_{p}$. Then it is transformed by prostaglandin- $H$-synthetase of thrombocytes $E_{1}$ and prostaglandin- $H$-synthetase of prostacyclins $E_{2}$, by forming, respectively, thromboxanes $T_{x}$ and prostacyclins $P$. Their levels depend on the activity of a dissipative outflow of either component. The output product of the system is a complex of the mentioned quantities formed at the aggregation of thrombocytes $T_{x}^{*}$. The regulation of the processes of hemostasis and thrombus-forming by prostaglandin is determined by the concentration $R$ of the regulating component, namely cyclic adenosine monophosphate (cAMP). This happens under the action of a negative feedback, which affects the level of activity of phospholipases of thrombocytes $A_{t}$ and endothelial cells $A_{p}$. As its value varies, the different modes are formed. 
The model involves the exchange of arachidonic acid between thrombocytes and endothelial cells $\left(A_{t} \leftrightarrow A_{p}\right)$, inactivation of enzymes at proteolysis, and the consumption of components in other processes.

The second input substance of the system is fat molecules $F$. They are transported by blood of arteries and affect the level of "bad cholesterol", LDLs. Its level is given by the variable $L$. LDLs are formed in liver and small intestine. In increased concentrations, LDLs influence the aggregation of thrombocytes $T_{x}^{*}$ and are accumulated in the walls of arteries, by forming oxidized lipoproteins $L^{*}$. The antithrombic system partially decomposes them. As a result of the deposition of "bad cholesterol", foamy fat-loaded macrophages are formed, which increases, in turn, the level of LDLs in artery. In the metabolic process, the positive feedback regulated by enzyme $E_{3}$ is formed. The accumulation of cholesterol in artery and the growth of patches cause thrombophilia. In this case, the blood-carrying channel of artery becomes narrower, and stenosis arises. Depending on the dissipation of LDLs, autooscillatory and chaotic modes can appear in the metabolic process of hemostasis of a blood vessel instead of stationary ones.

The mathematical model of this process is presented by Eqs. (1)-(12). This system includes 12 differential equations describing changes in the concentrations of components according to the general scheme given in Fig. 1. In the construction of the model, the law of mass action and the kinetics of enzyme catalysis are used. The equations involve the balance of masses for the intermediate products of reactions between separate stages of the metabolic process:

$$
\begin{aligned}
& \frac{d A_{t}}{d t}=\frac{k_{5} S}{\left(1+S+R^{2}\right)\left(1+k_{6} T_{x}\right)}- \\
& -\frac{k_{7} A_{t} E_{1}}{\left(1+A_{t}+k_{1} T_{x}\right)\left(1+E_{1}\right)}+ \\
& +k_{p} A_{p}-k_{t} A_{t}-\alpha_{1} A_{t} \\
& \frac{d T_{x}}{d t}=\frac{k_{7} A_{t} E_{1}}{\left(1+A_{t}+k_{1} T_{x}\right)\left(1+E_{1}\right)}-\frac{k_{8} T_{x}^{4}}{\left(k_{9}+T_{x}^{4}\right)}-\alpha_{2} T_{x}
\end{aligned}
$$
$\frac{d A_{p}}{d t}=\frac{k_{2} S R^{2}}{\left(1+S+k_{3} A_{p}\right)\left(k_{4}+R^{2}\right)}-\frac{k_{10} A_{p} E_{2}}{\left(1+A_{p}\right)\left(1+E_{2}\right)}+$
$+k_{t} A_{t}-k_{p} A_{p}-\alpha_{3} A_{p}$, $\frac{d P}{d t}=\frac{k_{10} A_{p} E_{2}}{\left(1+A_{p}\right)\left(1+E_{2}\right)}-\frac{k_{11} T_{x}^{*} P^{4}}{\left(1+T_{x}^{*}\right)\left(k_{12}+P^{4}\right)}-\alpha_{4} P$,

$\frac{d E_{1}}{d t}=\frac{k_{13} A_{T}}{\left(1+A_{T}\right)\left(1+R^{4}\right)}-$
$-\frac{k_{7} A_{t} E_{1}}{\left(1+A_{t}+k_{1} T_{x}\right)\left(1+E_{1}\right)}-\alpha_{5} E_{1}$,

$\frac{d E_{2}}{d t}=\frac{k_{15} A_{p} T_{x}^{* 4}}{\left(k_{16}+A_{p}\right)\left(k_{17}+T_{x}^{* 4}\right)}-$

$-\frac{k_{10} A_{p} E_{2}}{\left(1+A_{p}\right)\left(1+E_{2}\right)}-\alpha_{6} E_{2}$,

$\frac{d R}{d t}=k_{18} \frac{k_{19}+T_{x}^{* 4}}{k_{20}+\left(T_{x}^{*}+k_{21} R\right)^{4}}-\alpha_{7} R$,

$\frac{d T_{x}^{*}}{d t}=k_{8} \frac{L+T_{x}^{4}}{k_{9}+L+T_{x}^{4}}-\frac{k_{11} T_{x}^{*} P^{4}}{\left(1+T_{x}^{*}\right)\left(k_{12}+P^{4}\right)}-\alpha_{8} T_{x}^{*}$.

$\frac{d F}{d t}=F_{0}-l \frac{E_{3}}{1+E_{3}} \frac{F}{1+F+L}$,

$\frac{d L}{d t}=k \frac{E_{3}}{1+E_{3}} \frac{F}{1+F+L}-\mu \frac{L L^{*}}{1+L+L^{*}}$,

$\frac{d L^{*}}{d t}=\mu_{1} \frac{L L^{*}}{1+L+L^{*}}-\mu_{0} L^{*}$,

$\frac{d E_{3}}{d t}=E_{3_{0}} L^{*} \frac{F}{1+F} \frac{N}{N+L}-\alpha_{9} E_{3}$.

The model is specified by the following collection of parameters: $k=4 ; k_{1}=3 ; k_{2}=1 ; k_{3}=5 ; k_{4}=$ $=10 ; k_{5}=2.1 ; k_{6}=5 ; k_{7}=2 ; k_{8}=1.5 ; k_{9}=5$; $k_{10}=0.75 ; k_{11}=0.3 ; k_{12}=15 ; k_{13}=0.75 ; k_{15}=$ $=1 ; k_{16}=0.5 ; k_{17}=5 ; k_{18}=5 ; k_{19}=0.02 ; k_{20}=$ $=25 ; k_{21}=0.5 ; k_{p}=0.1 ; k_{t}=0.1 ; S=2 ; \alpha_{1}=$ $=0.01 ; \alpha_{2}=0.01 ; \alpha_{3}=0.01 ; \alpha_{4}=0.173 ; \alpha_{5}=$ $=0.05 ; \alpha_{6}=0.07 ; \alpha_{7}=0.2 ; \alpha_{8}=0.0021 ; \alpha_{9}=0.2 ;$ $F_{0}=0.01 ; l=2 ; \mu=4 ; \mu_{0}=0.42 ; \mu_{1}=2.3 ; E_{3_{0}}=$ $=11 ; N=0.05$. The study of solutions of the given mathematical model (1)-(12) was performed with the aid of the theory of nonlinear differential equations $[17,18]$ and the methods of modeling of biochemical systems, which were applied by the author in [19-40]. In numerical calculations, the Runge-Kutta-Merson method was used. The accuracy of calculations is about $10^{-8}$.

The other mathematical models of biochemical processes can be found, for example, in [41-44].

ISSN 2071-0194. Ukr. J. Phys. 2016. Vol. 61, No. 7 


\section{Results of Studies}

The presented mathematical model is given by the system of nonlinear differential equations (1)-(12), which describes the open nonlinear biochemical system of the hemostasis of a blood vessel in the presence of cholesterol in blood.

The study of the dynamics of the metabolic process of thrombosis-antithrombosis was carried out without cholesterol in blood in works [9-12]. Here, we calculated the modes depending on the value of the parameter of $\alpha_{7}$ characterizing the dissipation of cAMP $(R)$. Like the previous works, the system including cholesterol possesses two stationary modes. In Fig. 2, $a$ we show the dependence of the kinetics of $T_{x}^{*}$ on the parameter $\alpha_{7}$. For large $\left(\alpha_{7}=1\right)$ and small $\left(\alpha_{7}=0.005\right)$ values of this parameter, stationary modes are established. For $\alpha_{7}=1$, a thermodynamical branch (1) is formed, and, for $\alpha_{7}=0.005$, we observe the stationary dissipative structure (2). In the interval between these values for $\alpha_{7}=0.2$, the systems of thrombosis-antithrombosis are characterized by the autoperiodic mode (3). In other words, for the parameter of dissipation of cholesterol $\mu_{0}=0.439$, the kinetics of the process is invariable. But if $\mu_{0}=0.437$, the autoperiodic mode is replaced by the chaotic mode (4). Thus, the kinetics is determined by the interaction of the systems of thrombosis-antithrombosis and the rate of removal of cholesterol from a blood vessel. In Fig. 2, b, we show how the level of LDLs is changed, by depending on the type of a mode. In the stationary modes of hemostasis (1) and (2), the level of "bad cholesterol" is invariable. In the autooscillatory modes, it bears the chaotic character.

The studies indicate that, in the interval $\mu_{0} \in$ $\in(0.43,0.438)$, the stable autoperiodic modes of the system are transformed into chaotic ones.

Let us study the dependence of the oscillatory dynamics of the metabolic process of hemostasis on the dissipation of cholesterol from a blood vessel determined by the parameter $\mu_{0}$. In Fig. $3, a, b$, we show the phase-parametric diagram of the system for the variable $A_{t}(t)$ under the change in $\mu_{0}$ in the appropriate intervals. To construct the phase-parametric diagrams, we used the method of cutting. In the phase space of trajectories of the system, we place the cutting plane for $E_{2}=1.2$. As the trajectory crosses this
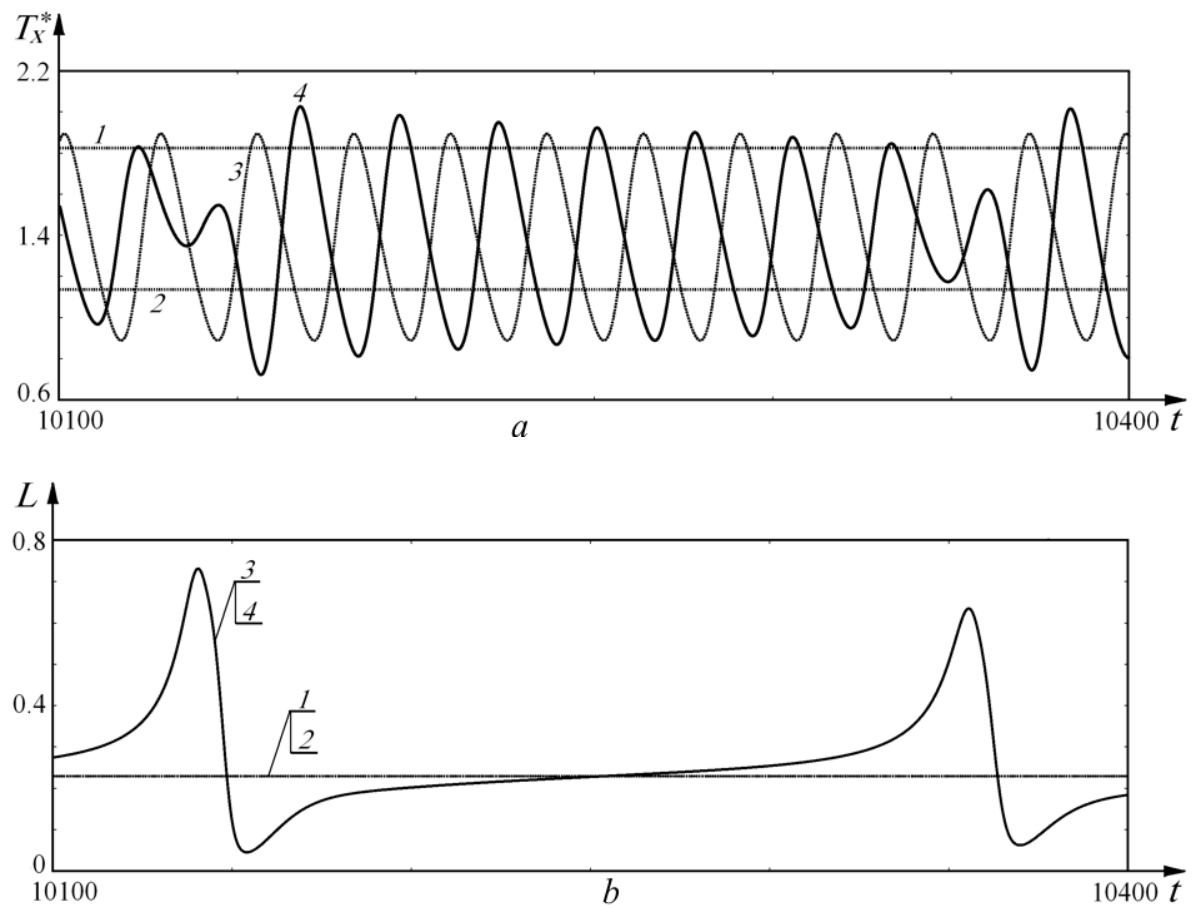

Fig. 2. Kinetic curves of the stationary mode for $\alpha_{7}=0.005$ and $\mu_{0}=0.42(1)$, stationary mode for $\alpha_{7}=1.0$ and $\mu_{0}=0.42$ (2), autoperiodic mode for $\alpha_{7}=0.2$ and $\mu_{0}=0.42$ (3), and a chaotic mode for $\alpha_{7}=0.2$ and $\mu_{0}=0.437$ (4) on planes: $\left(T_{x}^{*}, t\right)(a) ;(L, t)(b)$ 

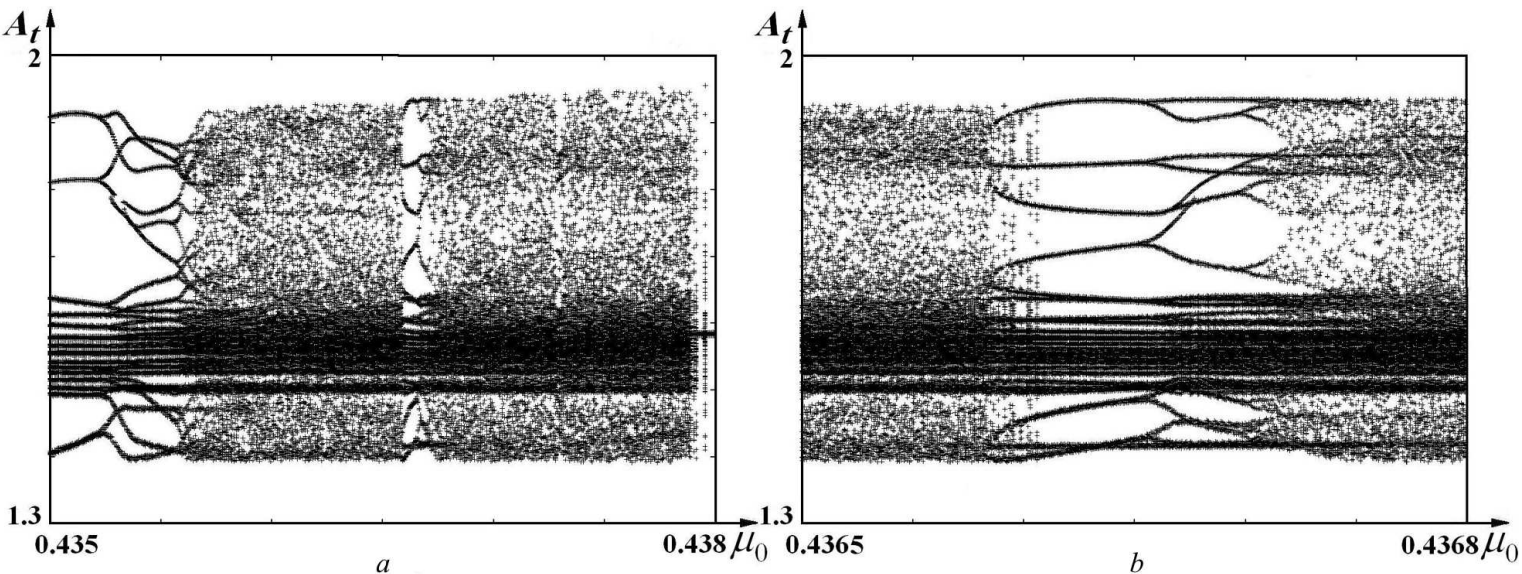

Fig. 3. Phase-parametric diagram of the system for the variable $A_{t}(t): \mu_{0} \in(0.435,0.438)(a) ; \mu_{0} \in(0.4365,0.4368)(b)$

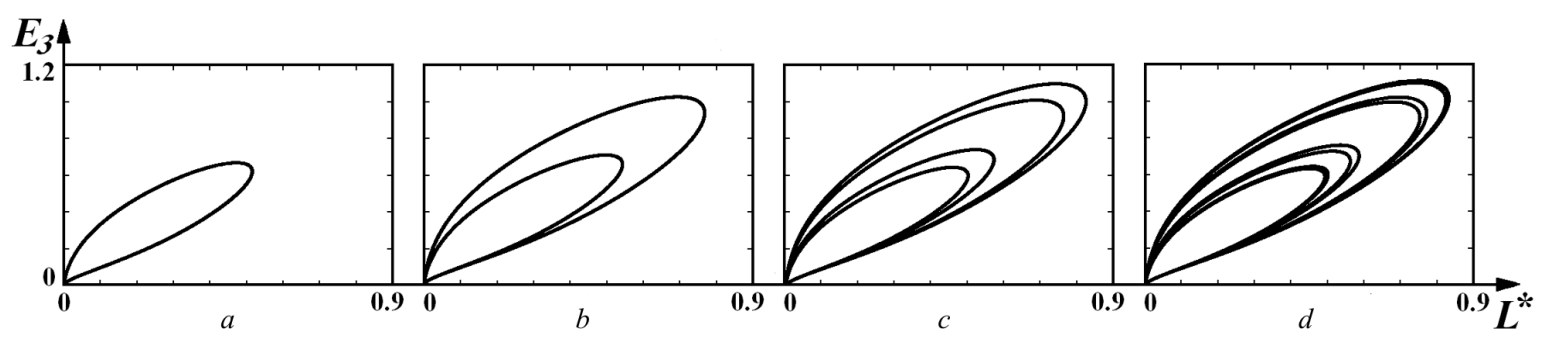

Fig. 4. Projections of the phase portraits of regular attractors of the system in the plane $\left(L^{*}, E_{3}\right): 1 \cdot 2^{0}$ for $\mu_{0}=0.43$ $(a) ; 1 \cdot 2^{1}$ for $\mu_{0}=0.435(b) ; 1 \cdot 2^{2}$ for $\mu_{0}=0.43555(c)$; and $1 \cdot 2^{4}$ for $\mu_{0}=0.43563(d)$

plane in some direction, we mark the value of chosen variable $\left(A_{t}(t)\right.$ in this case) on the phase-parametric diagram. Such choice is explained by the symmetry of oscillations of enzyme $E_{2}$ relative to this point in the multiply calculated earlier modes. For every value of $A_{t}(t)$, we mark the point of intersection of this plane by the trajectory in one direction, when the trajectory approaches an attractor. If a multiple periodic limiting cycle appears, the points marked on the plane will coincide in a period. In the case of the deterministic chaos, the points of intersection are located chaotically.

The scenario of the transition from autoperiodic modes to chaotic ones is presented in Fig. 4. The transition occurs due to the doubling of a period. As $\mu_{0}$ increases further, the autoperiodic mode is destroyed after the 4-th bifurcation, and chaos arises as a result of the intermittence.

It is seen from Fig. $3, b$ that the periodicity window arises between chaotic modes in the interval $\mu_{0} \in(0.43657,0.43672)$. The scenario of the appear-

\section{2}

ance of period doubling bifurcations in it and the formation of chaotic modes is analogous to that in Fig. 4. Some examples of the projections of phase portraits of a chaotic attractor are presented in Fig. 5, $a$, $b, c, d$. Figure $5, c, d$ indicates that the given strange attractor is formed due to a funnel. In the funnel, the trajectories, which approach one another in some directions and move away in other directions, are mixed. Under a small fluctuation, the periodic process becomes unstable, and the deterministic chaos arises.

While studying other modes of the phase-parametric disgrams in Fig. 3, $a, b$, it is impossible in proper time to determine the type of the attractor, to which a specific mode can be referred. It can be a multiple stable or quasistable autoperiodic cycle, as well as a strange attractor.

For the unambiguous identification of the type of obtained attractors and for the determination of their stability for the chosen parameters, we calculated the full spectra of Lyapunov's exponents $\lambda_{1}, \lambda_{2}, \ldots, \lambda_{12}$

ISSN 2071-0194. Ukr. J. Phys. 2016. Vol. 61, No. 7 

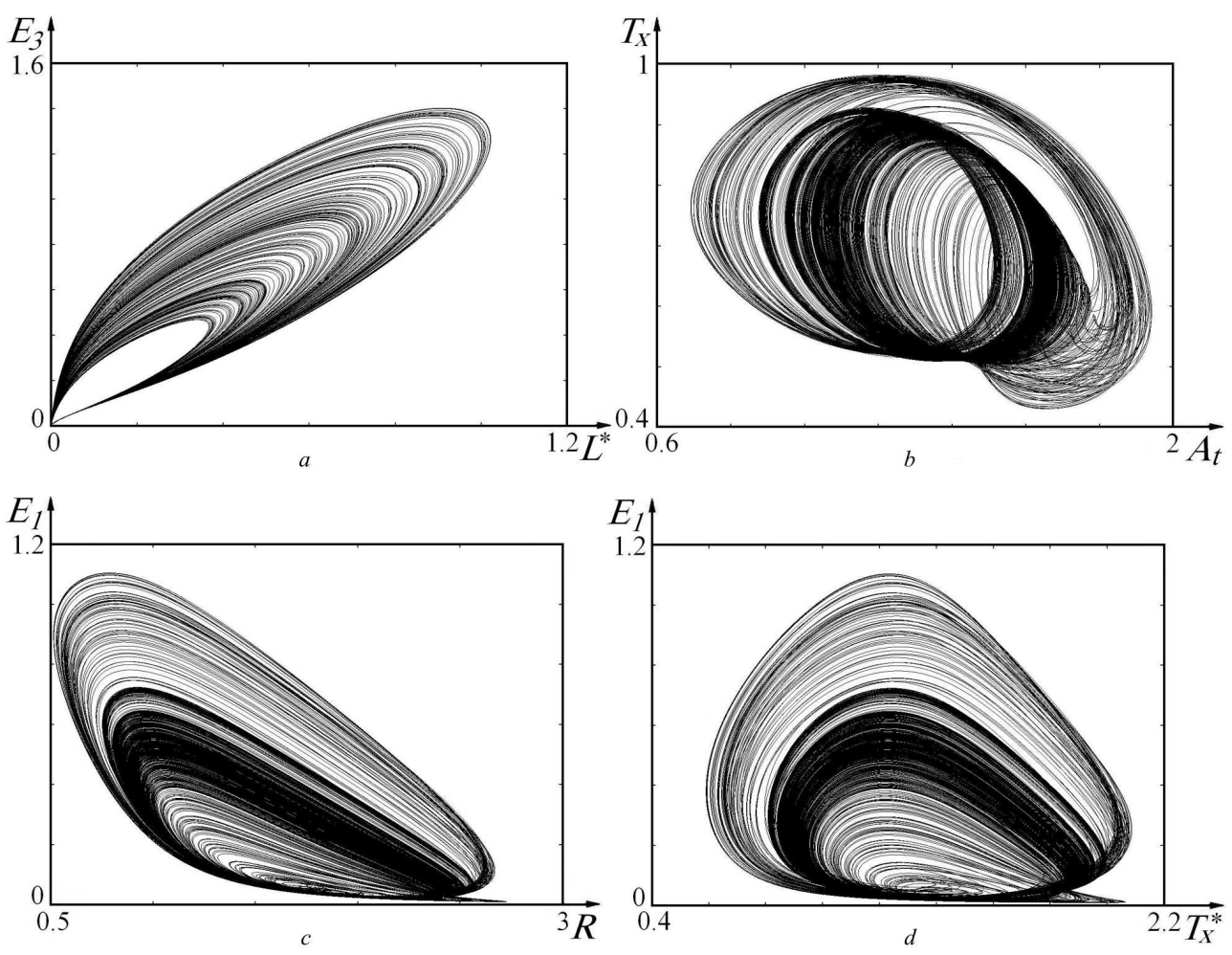

Fig. 5. Projections of phase portraits of the strange attractor $2^{x}$ for $\mu_{0}=0.437$ : in the plane $\left(L^{*}, E_{3}\right)(a)$, in the plane $\left(A_{t}, T_{x}\right)(b)$, in the plane $\left(R, E_{1}\right)(c)$, and in the plane $\left(T_{x}^{*}, E_{1}\right)(d)$

Lyapunov's exponents, KS-entropy, "predictability horizon",

and Lyapunov's dimension of the fractality of strange attractors calculated in different modes

\begin{tabular}{|l|c|c|c|c|c|c|c|}
\hline \multicolumn{1}{|c|}{$\mu_{0}$} & Attractor & $\lambda_{1}$ & $\lambda_{2}$ & $\lambda_{3}$ & $h$ & $t_{\min }$ & $D_{F_{r}}$ \\
\hline 0.43 & $1 \cdot 2^{0}$ & .00003 & -.00301 & -.06362 & - & - & - \\
0.43563 & $1 \cdot 2^{4}$ & .00003 & -.00282 & -.00546 & - & - & - \\
0.4365 & $2^{x}$ & .00170 & .00014 & -.00323 & .00170 & 588.24 & 2.53 \\
0.4368 & $2^{x}$ & .00181 & .00013 & -00368 & .00181 & 552.25 & 2.49 \\
0.437 & $2^{x}$ & .00192 & .00020 & -.00432 & .00192 & 520.83 & 2.44 \\
0.4375 & $2^{x}$ & .00244 & .00017 & -.00310 & .00244 & 409.84 & 2.79 \\
0.4378 & $2^{x}$ & .00263 & .00020 & -.00311 & .00263 & 380.23 & 2.85 \\
\hline
\end{tabular}

and their sum $\Lambda=\sum_{j=1}^{12} \lambda_{j}$ by Benettin's algorithm with orthogonalization of the perturbation vectors within the Gram-Schmidt method [18].

As an example for comparison, we present some results of calculations of the full spectra of Lyapunov's exponents in Table. To decrease table's size, we considered only the first three exponents $\lambda_{1}-\lambda_{3}$. The values of $\lambda_{4}-\lambda_{12}$ and $\Lambda$ are omitted, because they are not significant for the presentation of our results. The obtained numbers are rounded to the fifth decimal point. Based on the data in Table, we have calculated some other exponents for strange attractors.

With the use of Pesin's theorem [45], we calculated the KS-entropy (Kolmogorov-Sinai entropy) and Lyapunov's indicator "predictability horizon" [46]. Lyapunov's dimension of the fractality of strange 
attractors was found by the Kaplan-Yorke formula [47, 48]:

By the calculated exponents, we may judge about the difference of geometric structures of the given strange attractors.

Having calculated successively various strange attractors, we can indicate some regularity in the hierarchy of their chaotic behavior. According to changes in the exponents, the geometric shape of attractors of the system varies.

The autooscillations in the metabolic process of hemostasis of a blood vessel arise due to the interaction of two systems of blood (thrombosis and antithrombosis), which is regulated by the concentration of cyclic adenosine monophosphate. The presence of "bad cholesterol" in blood causes the desynchronization of these systems. In this case, the chaotic modes appear in the metabolism of hemostasis. LDLs affect the binding of thrombocytes and are deposited on the walls of vessels. This induces the autocatalysis of cholesterol in blood.

Thus, as the amount of cholesterol in blood changes, the hemostasis of blood vessels adapts to this change, by conserving its functionality in this case.

\section{Conclusions}

Within a mathematical model, we have studied the influence of "bad cholesterol" on the metabolic process of hemostasis of blood vessels. The system with metabolic process is considered as a dissipative system, whose input substances are arachidonic acid and low-density lipoproteins (LDLs). The interaction between the systems of thrombosis and antithrombosis leads to the appearance of stationary or autoperiodic modes. The presence of "bad cholesterol" breaks the balance of this process. It is the autocatalyst of the level of LDLs in blood. The interval of the intensity of dissipation of cholesterol from blood, in which the chaotic autooscillations in the metabolism of hemostasis can arise, is determined. The phaseparametric diagrams of autooscillatory modes, which depend on the dissipation of cholesterol from blood, are constructed. We have found the scenario of period doubling bifurcations existing until the aperiodic modes of strange attractors arise as a result of the intermittence. We have calculated the strange attractors, which appear due to the formation of the mixing funnel, and the full spectra of Lyapunov's exponents

\section{4}

for various modes. For the strange attractors, the KSentropies, "predictability horizons", and Lyapunov's dimensions of the fractality of attractors are determined. It is shown that the reason for changes in the metabolic process of hemostasis of blood vessels can be an insufficient intensity of dissipation of cholesterol from blood. The obtained results allow one to study the influence of low-density lipoproteins on the selforganization of the metabolic process of hemostasis of blood vessels and the development of stenosis. The reasons for changes of a physiological state of a blood vessel leading to thrombophilia are found. The influence of statins and other physiologically active substances on a decrease in cholesterol in blood vessels is estimated.

The work is supported by the project No.0113U001093 of the National Academy of Sciences of Ukraine.

1. Great Medicinal Encyclopedia (Sovetsk. Entsikl., Moscow, 1977), vol. 5, p. 223 (in Russian).

2. V.V. Verkhusha, V.M. Staroverov, and P.V. Vrzhesh, Biol. Membr. 11, No. 4, 437 (1994).

3. V.P. Baluda, M.V. Baluda, and I.I. Deyanov, Physiology of the System of Hemostasis (Meditsina, Moscow, 1995) (in Russian).

4. A.S. Shitikova, Thrombocytic Hemostasis (SPbSMU, St.Petersburg, 2000) (in Russian).

5. S.D. Varfolomeev, V.P. Gachok, and A.T. Mevkh, BioSystems. 19, 45 (1986).

6. S.D. Varfolomeev, A.T. Mevkh, and V.P. Gachok, Molek. Biol. 20, No. 4, 957 (1986).

7. V.P. Gachok, Kinetics of Biochemical Processes (Naukova Dumka, Kiev, 1988) (in Russian).

8. V.P. Gachok, Strange Attractors in Biosystems (Naukova Dumka, Kiev, 1989) (in Russian).

9. V.I. Grytsay, Visn. Kyiv. Univ. No. 3, 372-376 (2002).

10. V.I. Grytsay and V.P. Gachok, Visn. Kyiv. Univ. No. 4, 365 (2002).

11. V.I. Grytsay and V.P. Gachok, Visn. Kyiv. Univ., Ser. Fiz.Mat. Nauk. No. 1, 338 (2003).

12. V.I. Grytsay, Visn. Kyiv. Univ. No. 4, 379 (2003).

13. P. Libby, Circulation 91, No. 11, 2844 (1995).

14. M.J. Davies, Circulation, 94, No. 8, 2013 (1996).

15. J. Berlineret et al., Thrombosis and Haemostasis 78, No. 1, 195 (1997).

16. D. Steinberg, J. of Biol. Chem. 272, No. 34, 20963 (1997).

17. V.S. Anishchenko, Complex Oscillations in Simple Systems (Nauka, Moscow, 1990) (in Russian).

18. S.P. Kuznetsov, Dynamical Chaos (Nauka, Moscow, 2001) (in Russian).

ISSN 2071-0194. Ukr. J. Phys. 2016. Vol. 61, No. 7 
19. V.P. Gachok and V.I. Grytsay, Dokl. Akad. Nauk SSSR 282, 51 (1985).

20. V.P. Gachok, V.I. Grytsay, A.Yu. Arinbasarova, A.G. Medentsev, K.A. Koshcheyenko, and V.K. Akimenko, Biotechn. Bioengin. 33, 661 (1989).

21. V.P. Gachok, V.I. Grytsay, A.Yu. Arinbasarova, A.G. Medentsev, K.A. Koshcheyenko, and V.K. Akimenko, Biotechn. Bioengin. 33, 668 (1989).

22. V.I. Grytsay, Dopov. Nats. Akad. Nauk Ukr. No. 2, 175 (2000).

23. V.I. Grytsay, Dopov. Nats. Akad. Nauk Ukr. No. 3, 201 (2000).

24. V.I. Grytsay, Dopov. Nats. Akad. Nauk Ukr. No. 11, 112 (2000).

25. V.I. Grytsay, Ukr. J. Phys. 46, 124 (2001).

26. V.V. Andreev and V.I. Grytsay, Matem. Modelir. 17, No. 2, 57 (2005).

27. V.V. Andreev and V.I. Grytsay, Matem. Modelir. 17, No. 6, 3 (2005).

28. V.I. Grytsay and V.V. Andreev, Matem. Modelir. 18, No. 12,88 (2006)

29. V.I. Grytsay, Medium Romanian J. Biophys. 17, No. 1, 55 (2007).

30. V.I. Grytsay, Biofiz. Visn. No. 2, 92 (2007).

31. V.I. Grytsay, Biofiz. Visn. No. 2, 25 (2008).

32. V.I. Grytsay, Ukr. J. Phys. 55, No. 5, 599 (2010).

33. V.I. Grytsay and I.V. Musatenko, Ukr. Biochem. J. 85, No. 2, 93 (2013).

34. V.I. Grytsay and I.V. Musatenko, Ukr. J. Phys. 58, No. 7, 677 (2013).

35. V.I. Grytsay and I.V. Musatenko, Chaotic Modeling and Simulation (CMSIM) No. 4, 539 (2013).

36. V.I. Grytsay and I.V. Musatenko, Ukr. Biokhim. Zh. 85, No. 5, 191 (2013).

37. V.I. Grytsay and I.V. Musatenko, Biopolymers and Cell 30, No. 5, 404 (2014).

38. V. Grytsay and I. Musatenko, Chaotic Modeling and Simulation (CMSIM) 3, 207 (2014).

39. V. Grytsay, Ukr. J. Phys. 60, No. 6, 564 (2015).

40. V.I. Grytsay, Ukr. J. Phys. 60, No. 12, 1253 (2015).

41. Yu.I. Prylutskyy et al., Mater. Sci. \& Engineer. C 23, Nos. 1-2, 109 (2003).
42. A.D. Suprun, Yu.I. Prylutskyy, A.M. Shut, and M.S. Miroshnichenko, Ukr. J. Phys. 48, No. 7, 704 (2003).

43. Yu.I. Prylutskyy, A.M. Shut, M.S. Miroshnychenko, and A.D. Suprun, Inter. J. Thermophys. 26, No. 3, 827 (2005).

44. A.D. Suprun, A.M. Shut, and Yu.I. Prylutskyy, Ukr. J. Phys. 52, No. 10, 997 (2007).

45. Ya.B. Pesin, Usp. Mat. Nauk 32, 4, 55 (1977).

46. A.N. Kolmogorov, DAN SSSR 154, 754 (1959).

47. J.L. Kaplan and J.A. Yorke, Ann. N. Y. Acad. Sci. 316, 400 (1979).

48. J.L. Kaplan and J.A. Yorke, Functional Differential Equations of Fixed Points, edited by H.O. Peitgen, H.O. Walther (Springer, Berlin, 1979), p. 204.

Received 12.04 .16

\section{В.Й. Грицай}

\section{САМООРГАНІЗАЦІЯ}

ТА ХАОС В МЕТАБОЛІЗМІ ГЕМОСТАЗУ

У КРОВОНОСНІЙ СУДИНІ

$\mathrm{P}$ е $з$ ю м е

В даній роботі побудована математична модель метаболічного процесу становлення гемостазу в кровоносній судині. На відміну від раніш побудованої поліферментної простациклін-тромбоксанової системи крові, в цій моделі вперше враховано вплив на гемостаз рівня "поганого холестерина" - ліпопротеїдів низької щільності (ЛПНЩ). Знайдено умови, при яких виникає самоорганізація системи, утворюються режими автоколивань та хаосу в метаболічному процесі, що впливає на становлення гемостазу та виникнення тромбофілії. За допомогою фазопараметричної діаграми досліджено сценарій їх виникнення. Знайдено біфуркації подвоєння періоду та переходу до хаотичних коливань внаслідок перемєжаємості. Отримані дивні аттрактори утворюються внаслідок воронки перемішування. Розраховані їх повні спектри показників Ляпунова, КСентропії, "горизонти передбачуваності" і ляпуновські розмірності дивних аттракторів. Зроблено висновки про причини зміни циклічності в даному метаболічному процесі, його стійкості і фізіологічному прояві в кровоносній системі. Оцінено роль фізіологічно-активних речовин для зменшення рівня холестерина в судинах. 